Periodica Polytechnica Architecture, 50(2), pp. 124-131, 2019

\title{
Analysis of the Crack Resistance of the Cement Stone and Roche
}

\author{
Vladimir Erofeev ${ }^{1}$, Irina Maksimova², Nikolay Makridin², Alexey Bulgakov³ ${ }^{3}$, Salman Al-Dulaimi ${ }^{1}$ \\ ${ }^{1}$ Department for Building Materials and Technologies, Faculty of Architecture and Civil Engineering, \\ National Research Mordovia State University. N.P. Ogareva, 430005, Saransk, Russia \\ 2 Department for Technologies of Building Materials and Woodworking, Faculty of Technology, \\ Penza State University of Architecture and Construction 440028, Penza, Russia \\ ${ }^{3}$ Department for Construction Management, Faculty of Construction and Architecture, \\ Southwest State University, 305040, Kursk, Russia \\ * Corresponding author, e-mail: a.bulgakow@gmx.de
}

Received: 12 October 2018, Accepted: 23 December 2018, Published online: 06 November 2019

\begin{abstract}
The crack resistance is the most important parameter of strength. It characterizes the ability of a material structure to resist the beginning of the movement and development of cracks at mechanical and other force impacts and is the most important parameter of the limit state of the structure. In this regard, the evaluation of parameters of the mechanics of rocks, used as fillers (dispersed phase) and the cement stone (matrix phase) for concrete, influencing factor of the actual strength of the cement composite, is not only of theoretical interest, but also of great practical importance, since the issues in regards to the problem of choosing fillers are very poorly addressed in the professional literature, especially re the new generation of concretes.
\end{abstract}

\section{Keywords}

cement stone, compressive strength, flexural tensile strength, stress intensity factor, fracture energy, total specific acoustic emission energy, crack propagation force

\section{Introduction}

The new approach to the strength issue can be one of the ways to clarify further the nature of the mechanics of concrete and its structural elements under load. The approach is based on a detailed study of the process of initiation and development of cracks from the standpoint of physics and fracture mechanics using the method of acoustic emission (AE) grounded on registration of the ultrasound signals generated in the material during its cracking under stresses as the initial position of the fracture mechanics of materials is that the destruction is a result of cracks development which occur either prior to application of stress, or during loading.

The event of acoustic emission is reviewed in the great number of experimental and theoretical works described in monographs, reviews, and articles (Lange, 1978; Greshnikov and Drobot, 1976; Pochtovik et al., 1977; Ivanoc and Belov, 1981; Muravin et al., 1982; Evans and Langdon, 1980; Bartenev et al., 1991; Makridin et al., 1986; Makridin et al., 2001; Perfilov, 2000; Lenain, 1981; Makridin et al., 2007).
In this work, the comparative identification of process of destruction of the samples of the cement stone of different ages, granite, limestone, marble and artik tuff was performed using the method of acoustic emission, as those samples represent the main components of the structure of cement composites, which are determining their crack resistance.

The technical specifications of the acoustic-emission device are indicated in the work (Makridin et al., 2007).

\section{Research}

The test samples of the cement stone of two batches at water-cement ratio of 0.24 were made to carry out the research. At this, the samples of the first batch were made without the high range water reducer, the samples of the second batch were made using the high range water reducer S-3 in the number of $1 \%$ of the cement mass. The $40 \times 40 \times 160 \mathrm{~mm}$ test samples, type I under GOST 29167 were created by means of joggling the water-cement paste during preparation of the samples. 
Samples of cement stone based on Sulfate-Resistant Portland Cement 400 at W/C ratio of 0.24 , which corresponded to the normal consistency of the water-cement paste, were tested after steam curing at the age of 28, 420 days and 18 years at the same temperature and humidity conditions during mechanical testing.

For comparison purposes, the granite, limestone, marble and artic tuff test samples of the following relevant sizes were made: $27 \times 40 \times 160 ; 31 \times 41 \times 160 ; 21 \times 40 \times 160$ and $40 \times 40 \times 160 \mathrm{~mm}$. Cuts at the middle of the samples for $1 / 3$ of their height (thickness) were made using $1 \mathrm{~mm}$ thick diamond point cutter.

The following items are taken as the informative parameters of the acoustic emission when studying the process of the crack resistance of the cement stone samples: a number of the ultrasound pulses of acoustic emission $N_{1}$ and $N_{2}$ at two discrimination levels correspondingly, with the amplitudes $A_{1}$ and $A_{2}$ and ratio of $N_{1} / N_{2}$. After the pulses preamplifier, the pulses of the acoustic emission with the amplitude $A_{1}$ were recorded within the range of (0.05-0.50) $\mathrm{V}$ and the pulses of acoustic emission with the amplitude $A_{2}$, which is higher than $0.50 \mathrm{~V}$ correspondingly. The ratio $N_{1}\left(A_{1}\right) / N_{2}\left(A_{2}\right)$ indicates the development of the deformation and destruction of the material at different scale levels and different nature of the generated signals. Pulses of the acoustic emission of the small amplitude $A_{1}$ characterize the plastic flows of the material at the beginning of the crack apex and occurrence and development of the material structure defects generate signals of acoustic emission of the relatively bigger amplitude $A_{2}$.

In Figs. 1, 2 the kinetics of the acoustic emission signals with the discrimination amplitudes respectively and the ration of the ultrasound pulses $N_{1} / N_{2}$ of the small and big amplitudes at the curve of the samples loading for two most distinctive of the cement stone contents without the high range water reducer which were used for identification of the process of the destruction of the cement stone in the real time.

According to analysis of the dependences in Figs. 1, 2, first of all, it should be noted that, at other conditions of the registration of parameters of the acoustic emission being equal, the intensity of the signal depending on the level of loading of the test samples of cement stone of the compared batches is significantly lower at the age of 28 days, than at 420 days and moreover at 18 years.

Comparing reviewed dependences of the test samples from batches 1 and 2 at the age of the cement stone of 28 days, which differ from each other by the presence of the
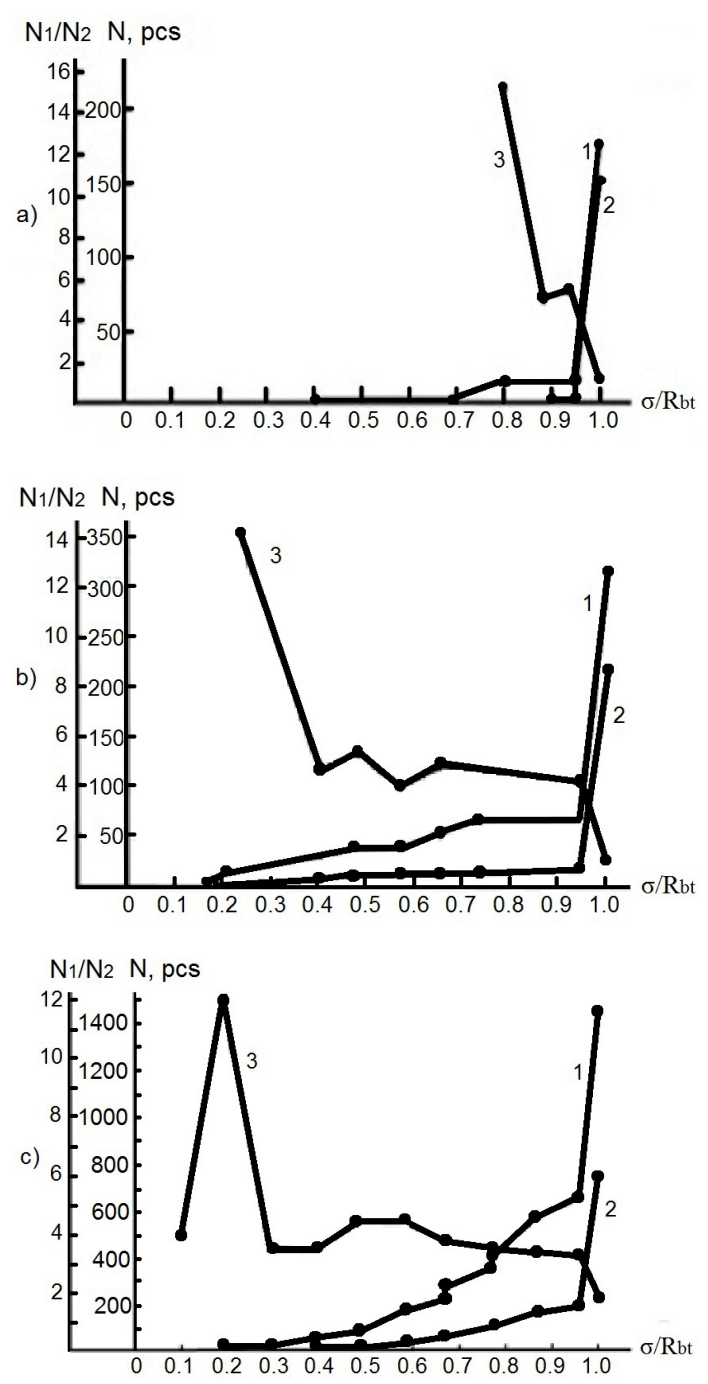

Fig. 1 Dependence of the quantity $\left(N_{1}\right.$ and $\left.N_{2}\right)$ of AE signals with amplitudes $A_{1}$ and $A_{2}$ and of ratio of $N_{1} / N_{2}: 1-$ Amplitude of the AE signal $A_{1}=0.05-0.50 \mathrm{~V} ; 2-$ Amplitude of the AE signal $A_{2}>0.50 \mathrm{~V}$; 3 - Ratio of the quantity $\left(N_{1}\right.$ and $\left.N_{2}\right)$ of AE signals; a) age of the cement stone -28 days; b) age of the cement stone -420 days; c) age of the cement stone -18 years

high range water reducer in the composition of the water - cement paste, it should be noted, that the first acoustic emission signals with the amplitude $A_{1}$ at the diagrams of loading of samples from batches 1 and 2 were recorded at the loading levels of 0.4 and $0.96 R_{b t}$ respectively, and the acoustic emission signals with the amplitude $A_{2}$ at the loading levels of 0.8 and 0.96 of $R_{b t}$, respectively. At this, the number of pulses of acoustic emission $N_{1}$ and $N_{2}$ with the amplitude $A_{1}$ and $A_{2}$ at the ceiling loading level (0.95-0.96) $R_{b t}$ comprised 17 and 3 for the samples from the batch 1 , and 5 and 1 for the samples from batch 2, which corresponded to the ratio of $N_{1}\left(A_{1}\right) / N_{2}\left(A_{2}\right)$, as 5.6 and 5.0. At 

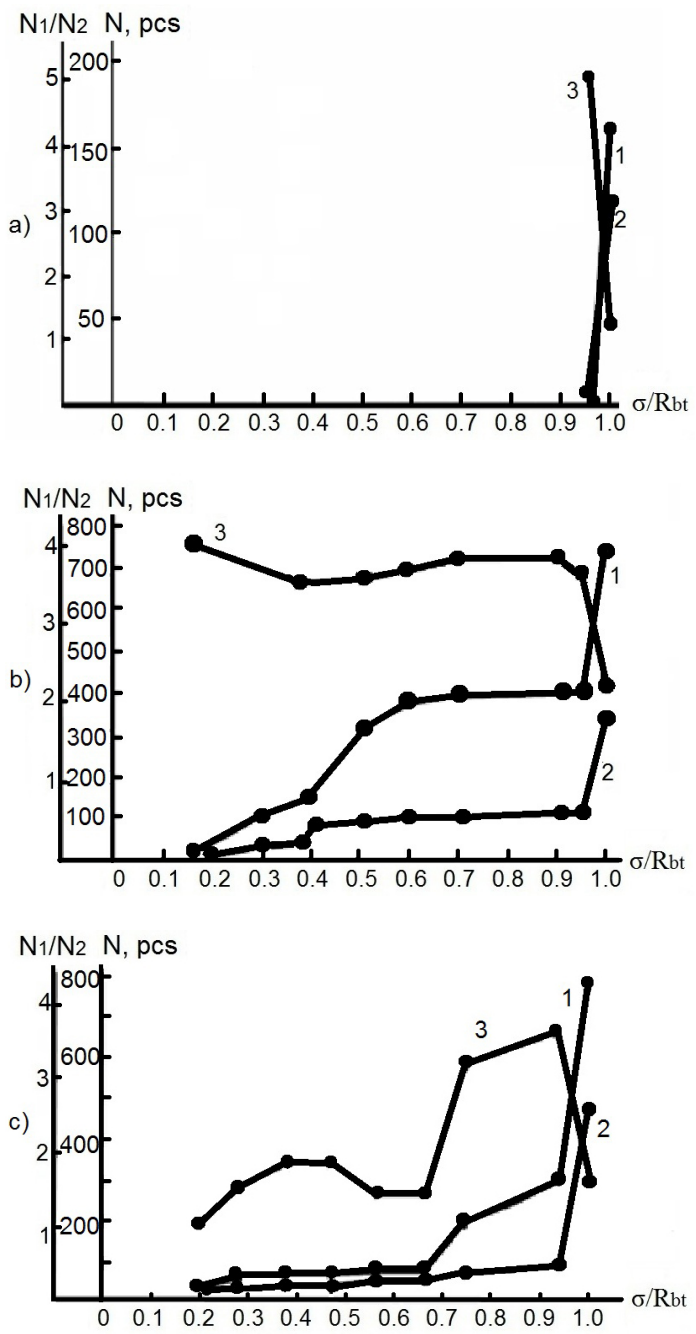

Fig. 2 Dependence of the quantity $\left(N_{1}\right.$ and $\left.N_{2}\right)$ of AE signals with amplitudes $A_{1}$ and $A_{2}$ and of ratio of $N_{1} / N_{2}$ from batch 1 without the high range water reducer: 1 - Amplitude of the AE signal $A_{1}=0.05-0.50$ $\mathrm{V} ; 2$ - Amplitude of the AE signal $A_{2}>0.50 \mathrm{~V} ; 3$ - Ratio of the quantity ( $N_{1}$ and $N_{2}$ ) of AE signals; a) age of the cement stone - 28 days; b) age of the cement stone -420 days; c) age of the cement stone -18 years

the complete destruction of the samples, there were registered 180 and $155 ; 160$ and 120 pulses with the amplitude $A_{1}$ and $A_{2}$, respectively, which were equal to the ratio of $N_{1}\left(A_{1}\right) / N_{2}\left(A_{2}\right)-1.2$ and 1.33. In our opinion, the quantitative and the qualitative difference of the generated signals of acoustic emission at the diagram of the loading of the test samples from batches 1 and 2 indicates the influence of the specifics of the chemical and process modification of the disperse and crystallite structure of the cement stone, both for the mechanism of the structure formation and for the quantitative values of the strength $R_{b t}$ and $R_{c}$.

Analysis of the dependence of the change of generated signals of the acoustic emission depending on the intensity of loading for the cement stone samples at the age of 420 days when the hardening of structure in time results in the transition of the adhesive contacts of the electromagnetic and electrostatic nature into the crystallization bonds of the valence nature (Sychov, 1974) and leads to the significant increase of strength $R_{b t}$ up to 6.38 and 6.69 $\mathrm{MPa}$ for the batches 1 and 2 samples respectively. On the other hand, it witnesses of the ultimately different qualitative and quantitative nature of the change of the pulses of the acoustic emission generated by the samples of the compared batches.

Thus, the first signals of the acoustic emission, both with the amplitude $A_{1}$, and with the amplitude $A_{2}$ were recorded from the samples of the compared batches at the initial level of the loading, i.e. at the levels of (0.14-0.16) $R_{b t}$. According to the characteristic curves in Figs. 1, 2, further loading of the samples is characterized by the quite intensive radiation of the pulses of the acoustic emission in regards to the samples of the cement stone of the age of 28 days. At this, samples of the batch 2 showed the biggest intensity of the acoustic emission signals, which correlates with the parameter of the cement stone structure change and the increase of its strength at the age of 420 days.

The dependences $N_{1}\left(A_{1}\right) / N_{2}\left(A_{2}\right)$ for the samples of this age quite clearly reflect the fluctuations of this ratio and the stochastic nature of the amplitude-energy distribution of acoustic emission pulses at the curve of loading the test samples.

At the ceiling loading level $(0.94-0.97) R_{b t}$ of the samples of the 420 days age of the batches 1 and 2, the recorded pulses of acoustic emission with the amplitudes $A_{1}$ and $A_{2}$, comprised 67 and 16; 396 and 111, respectively, which were equal to the ratio of $N_{1}\left(A_{1}\right) / N_{2}\left(A_{2}\right)$ as 4.2 and 3.6. At the complete destruction of the samples, there were registered 317 and 218; 741 and 341 pulses of AE with $A_{1}$ and $A_{2}$, respectively, which were equal to the ratio of $N_{1}\left(A_{1}\right) / N_{2}\left(A_{2}\right)-1.45$ and 2.2.

Before we analyze the dependence of the change of the generated pulses of acoustic emission on the intensity of loading the samples of the cement stone of the age of 18 years, it should be noted that at this age both its own deformations and internal stresses, and the formation of condensate-crystallization structure become apparent in the structure of the cement stone in full. As a result of the above the strength $R_{b t}$ of the compared batches of the samples comprised 5.36 and 6.53 MPa (Makridin et al., 2011), respectively, i.e. the reduction of $R_{b t}$ by 16 and $2 \%$ for the batches 1 and 2, respectively, occurred in regards to the 
sample of the age of 420 day. It is fully compliant with the accepted technology of modification and structure formation of the cement stone.

However, in spite of the reduction of $R_{b t}$, it should be emphasized that the intensity of the acoustic emission signals radiation by these samples both with the amplitude $A_{1}$, and with the amplitude $A_{2}$ increased even more. Probably, it is caused by the structure defects propagation due to its own stresses, which are the additional sources of the generation of acoustic emission signals. The nature of the change of the dependences of radiation of acoustic emission pulses at the loading curve for the 18 years old samples is indeed the same as for the 420 days old samples. At this the acoustic parameter of the ratio $N_{1}\left(A_{1}\right) / N_{2}\left(A_{2}\right)$ of the compared batches of samples at the age of 18 years under the ceiling loading level equal to (0.93-0.97) $R_{b t}$, comprised 3.3 and 3.6, respectively, and at the complete destruction it made 1.9 and 1.7, respectively, for the samples of batches 1 and 2 .

Comparing the results of the research on the studying of the nature of the change of the radiation of the acoustic emission pulses and its parameters depending on the intensity of loading in the time period from 28 days to 18 years, it should be noted that the information obtained using the acoustic emission method can be taken as a basis of identification of the process of the cement stone destruction under load with rather specific determination of plastic and brittle constituents of the process based on the quantitative values of the acoustic parameter $N_{1}\left(A_{1}\right) / N_{2}\left(A_{2}\right)$ at the loading curve, which values quite clearly reflect the impact of the high range water reducer on the forming of the disperse and crystallite structure of the cement stone and its mechanics under load.

Resulting from the analysis of the dependences in Fig. 3 under otherwise equal conditions, the recording of the acoustic emission parameters, signals intensity and the nature of the change of the parameters radiation depending on the level of loading of the test samples made of the materials of the compared rocks significantly differ from each other. It allows passing judgment on the strength properties of the material, on the development of the plastic and brittle constituents of the process of destruction in real time as well as making forecasts on the further serviceability and limiting states of the material structure.

Limestone and tuff (Fig. 3) were recorded at the levels of loading of $0.067 ; 0.66 ; 0.4$ and $0.2 R_{b t}$, respectively, and the signals of acoustic emission with the amplitude $A_{2}$ at the loading levels of $0.333 ; 0.89 ; 0.4$ and $0.6 R_{b t}$, respectively. At this, the number of ultrasound pulses of acoustic emission $N_{1}$ and $N_{2}$ with the amplitudes $A_{1}$ and $A_{2}$ at the ceiling loading level (0.9-0.96) comprised 387 and 88; 190 and 58; 183 and 9; 158 and 24, respectively, which corresponded to the ratio $N_{1}\left(A_{1}\right) / N_{2}\left(A_{2}\right)$, equal to $4.4 ; 3.3$; 20 and 6.6. At the complete destruction of the compared samples, there were registered 5243 and 3196; 1130 and 396; 1177 and 481; 824 and 460 ultrasound pulses with the amplitudes $A_{1}$ and $A_{2}$, respectively, which matched the ratio $N_{1}\left(A_{1}\right) / N_{2}\left(A_{2}\right)$ equal to $1.64 ; 2.85 ; 2.45 ; 1.79$.

Comparing the dependences of the change of the generated ultrasound pulses of acoustic emission on the intensity of the loading of the rock materials samples (Fig. 3) which differ not only by the origin, but also by the density, modulus of elasticity, internal friction coefficient and the destruction energy (Makridin et al., 2012), it should be noted that there are both the qualitative and the quantitative difference of the analysed dependences. It reflects influence of the whole complex of the mentioned above factors onto the mechanism of destruction of the disperse and crystallite structure of these rocks under load.

In order to have more efficient analysis of dependences of the change of the generated ultrasound pulses of acoustic emission of the rocks on the loading intensity, deeper understanding of destruction process and identification of the material parameters, which determine their crack resistance, it is feasible to perform the analysis taking into consideration the main physical and mechanical properties of the rocks, specified in a Table 1, obtained by us experimentally and which values are in compliance with the data of other researchers.

Acoustic parameter $N_{1}\left(A_{1}\right) / N_{2}\left(A_{2}\right)$ can be used for identification of destruction of the compared rocks samples at the loading curve considering different physical phenomena, which underlie the generated acoustic emission signals with the amplitudes $A_{1}$ and $A_{2}$, and in general case showing the contribution of the elastic (brittle) constituents to the general process of the force destruction (Belikov et al., 1970).

Specifics of the characteristic curves of the granite samples in Fig. 3 a), which polycrystalline fine grained structure is a typical composite structure, is that the acoustic parameter $N_{1}\left(A_{1}\right) / N_{2}\left(A_{2}\right)$ reflects the fluctuations of this ratio and the stochastic nature of the amplitude distribution of acoustic emission ultrasound pulses at the curve of loading. At this, the stochastic nature of the acoustic parameter $N_{1}\left(A_{1}\right) / N_{2}\left(A_{2}\right)$ change is worth noticing as well as its quite vivid change at the specific stages of loading till the complete ceasing of the radiation 

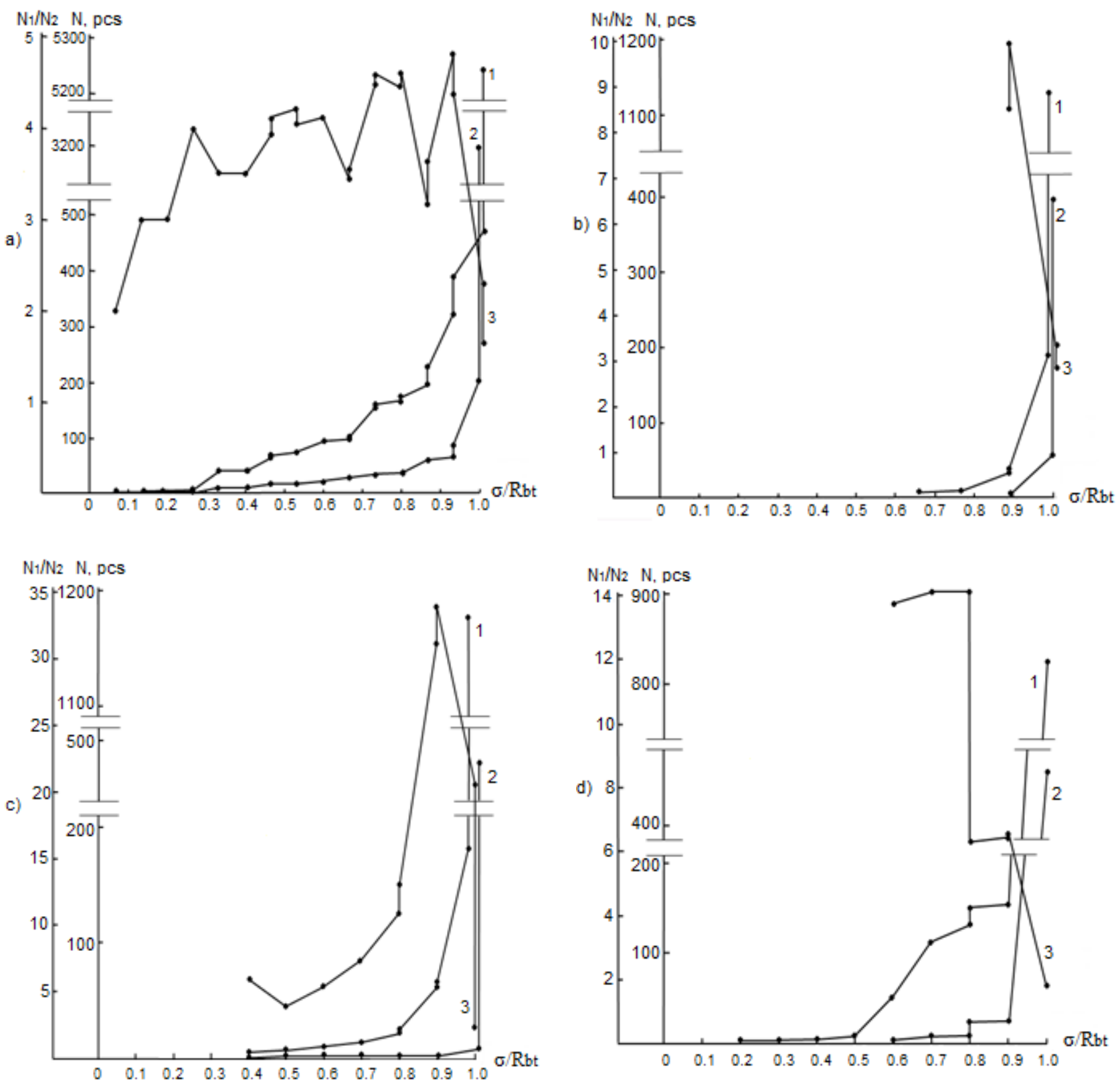

Fig. 3 Dependence of the number $\left(N_{1}\right.$ and $\left.N_{2}\right)$ of AE signals, respectively, with the amplitudes $A_{1}$ and $A_{2}$ and the ratio $N_{1} / N_{2}$ of the granite (a), marble (b), limestone (c) and artic tuff (d) samples of Type I under GOST 29167 at three point bending on the loading intensity: $1-\mathrm{Amplitude}$ of the AE signal $A_{1}=0.05-0.50 \mathrm{~V} ; 2-$ Amplitude of the AE signal $A_{2}>0.50 \mathrm{~V} ; 3-$ Ratio of the quantity $\left(N_{1}\right.$ and $\left.N_{2}\right)$ of AE signals

Table 1 The main physical and mechanical properties of the roche

\begin{tabular}{lcccc}
\hline \multirow{2}{*}{ Parameters } & \multicolumn{3}{c}{ Roche } \\
\cline { 2 - 5 } & Granite & Marble & Limestone & Artic Tuff \\
\hline Density, $\mathrm{gr} / \mathrm{cm}^{3}$ & 2.78 & 2.73 & 2.44 & 1.17 \\
Strength $R_{b t}, \mathrm{MPa}$ & 15.57 & 23.47 & 8.11 & 6.52 \\
Dynamic modulus of elasticity, $\mathrm{MPa}$ & 40840 & 89780 & 34120 & 11830 \\
Internal friction coefficient & 0.01224 & 0.00192 & 0.00519 & 0.00320 \\
Limit deformability of the tension region, $\mathrm{mm} / \mathrm{m}$ & 0.36 & 0.30 & 1.07 & 0.31 \\
Conditional critical coefficient of the stresses intensity, MPa $\mathrm{m}^{0,5}$ & 1.270 & 1.684 & 0.785 & 0.614 \\
Energy of destruction at the limit deformability, $\mathrm{J} / \mathrm{m}^{2}$ & 296 & 281 & 753 & 162 \\
\hline
\end{tabular}

Where : $\mathrm{MPa}=145 \mathrm{psi} ; 1 \mathrm{~mm}=0.0394 \mathrm{in}$. 
of the acoustic emission signals with the amplitudes $A_{1}$ and $A_{2}$, which is reflected both in the nature of the curves slope and in the kinetics of the generated acoustic emission ultrasound pulses with the above amplitudes at the loading curve. Stochastic behaviour of the acoustic emission at the curve of loading is caused by the non-equilibrium phase transitions in the material composite structure. From the standpoint of the synergetic, they allow to justify both the presence of the discrete levels of energy per the unit of length of the structure defect development and the change of destruction micro mechanism at the bifurcation point, reaching which the properties change in a stick-slip way and abruptly due to the self-organization of the process (Bobryshev et al., 1994).

In the Fig. 3 b) the characteristic curves of the change of the generated ultrasound pulses of acoustic emission for the samples from the tight white facing Ural marble are presented. The above mentioned marble has tight, quite homogeneous microcrystalline structure.

Considering the aggregate of the physical and mechanical properties of the compared rocks, indicated in the Table 1.

The joint analysis of the characteristic curves of the Figs. 3 a) and b) allows to state the essential difference in the mechanical properties of granite and marble. Thus, the numeric value of the bending resistance, dynamic modulus of elasticity and conditional critical coefficient of the intensity of the marble samples stresses exceeded the values of the mechanical properties of granite samples in 1.5; 2.2 and 1.3 times, respectively. At this, the values of the internal friction coefficient, which is a measure of the internal friction of the structure of the real materials were, on the contrary, 6.38 times higher than the granite samples had. From the standpoint of the mechanics of the material under dynamic load, it means that the granite possess better ability to transform the mechanical energy, conveyed to it during the deformation process, into heat irreversibly. In other words, the portion of the density of the energy of the micro plastic deformation in the area of the appearance of the new surface of the total effective surface energy of the material is considerably higher in the samples of granite, than in the marble samples.

It is the qualities and the specifics of the compared materials micro-structure in particular that determine the crucial difference in the characteristic curves of the change of the generated ultrasound pulses of acoustic emission at the loading diagram of granite and marble test samples. This difference is that the first signals of acoustic emission with the amplitude up to $0.5 \mathrm{~V}$ were recorded at the granite samples under intensity of the loading of $0.067 R_{b t}$, and at the marble samples - under $0.66 R_{b t}$. In their own turn, the first signals of acoustic emission with the amplitude higher than $0.5 \mathrm{~V}$ were recorded at the level of loading of 0.267 and $0.89 R_{b t}$, respectively. At this, the nature of the characteristic curves of generated ultrasound pulses of AE shown at Figs. 3 a) and b) also significantly differs. It is caused by the difference of both the mechanics and the micro mechanisms of the processes of destruction of the rock materials of different genesis. In this case the value of acoustic parameter $N_{1}\left(A_{1}\right) / N_{2}\left(A_{2}\right)$ very clearly reflects the identification of the process of the samples destruction considering the different physical phenomena, which underlie the generated signals with the amplitudes $A_{1}$ and $A_{2}$, which moves the researcher closer to the understanding of the destruction process and identification of the materials parameters which determines its crack resistance. It should be noted that the nature of the change and quantitative values of acoustic parameters at the curve of loading of the samples are determinative as on its base we can forecast limit states of the materials structure and its cracking resistance under force influence. The wider the range of the loading intensity which is covered by the acoustic parameter and the bigger its quantitative value, the bigger its reflection of the input of the plastic constituent into the general process of destruction and vise versa, which results from the plots of Figs. 3 a) and b. In it own turn, quite sharp reduction of the quantitative value of the acoustic parameter which reflects the hopping of the destruction micro mechanism forecasts the occurrence of the material limit state of the structure.

In Figs. 3 c) and d) the characteristic curves of the change of the generated ultrasound pulses of acoustic emission depending on the intensity of loading the limestone and artic tuff samples.

Comparing the characteristic curves in Figs. 3 b) and c) obtained at the samples of the carbonate rock, that is marble and limestone, respectively, it should be noted that the marble density comprised 2.73, while the limestone one made $2.44 \mathrm{~g} / \mathrm{cm}^{3}$. At this, as it appears from the Table 1, the values of strength, dynamic modulus of elasticity and conditional critical coefficient of the intensity of the marble samples stresses exceeded the same values of the limestone samples significantly. However, the quantitative values of the limit deformability of the tension region, the destruction energy at the limit deformability and of the internal friction coefficient were in their own turn much higher at the limestone samples than at the marble samples. 
Such difference of the physical and mechanical properties of the marble and the limestone is determined by both the porosity and the micro-structure of the carbonate rock. Marble micro-structure was homogeneous and microcrystalline, while the limestone had noticeable large grained structure. With that, the difference between the structural and mechanical parameters of marble and limestone samples determines the significant difference of the characteristic curves of the generation of the acoustic emission ultrasound pulses depending on the intensity of loading.

A distinctive feature of characteristic curves of limestone samples (Fig. 3 c)) in comparison with marble samples (Fig. 3 b)) is that given the lower modulus of elasticity value, higher value of limit deformability and the internal friction coefficient first ultrasonic pulses of acoustic emission with amplitude $A_{1}$ and $A_{2}$ at the loading diagram the limestone samples were recorded at the loading level of $0.4 R_{b t}$. A further increase in the intensity of the load up to the level of $0.9 R_{b t}$ was accompanied by practically only the increase of the number of $\mathrm{AE}$ signals with amplitude $A_{1}$, resulting in abnormal growth of the acoustic parameter $N_{1}\left(A_{1}\right) / N_{2}\left(A_{2}\right)$ to the quantitative value of 34 , while it was equal to 10 for the samples of marble at a similar level of intensity of the load, i.e. $0.9 R_{b t}$. It was noted above that the quantitative values of the acoustic parameter in the loading curve reflect the relative input of plastic and elastic (brittle) components in the overall process of deformation and destruction of the material under load. In this regard, we can say that by the nature of the change of the generated ultrasonic pulses of acoustic emission of acoustic parameter $N_{1}\left(A_{1}\right) / N_{2}\left(A_{2}\right)$ depending on the intensity of the loading, the limestone carbonate rock was characterized by a higher cracking resistance than the carbonate rock of marble. It is consistent with the quantitative values of the energy of destruction of these rocks in $\mathrm{J} / \mathrm{m}^{2}$ which were indicated in the Table 1.

Based on the analysis of characteristic curves of Fig. 3 d), obtained at the samples of artic tuff, it should be noted that by the nature of the change of the generated ultrasonic pulses of acoustic emission at the curve of loading, the artic tuff is virtually no different from reviewed dependences of other rocks. The distinguishing feature includes fewer ultrasonic pulses of acoustic emission at the curve of loading, which is caused by the porosity of the structure and a lower density of tuff, equal to $1.17 \mathrm{~g} / \mathrm{cm}^{3}$ and, therefore, lower potential energy during the deformation of the test sample.

\section{Conclusion}

Thus, a comprehensive study of physical and mechanical properties and of changes of the generated ultrasonic pulses of acoustic emission at the loading diagram of the type I test samples of rocks of different genesis and the cement stone of different structure and age, tested under GOST 29167 using acoustic emission method to study the process of destruction:

- a scientifically grounded methodological approach to the integrated assessment of the mechanical behaviour under force impact and to the structural selection of natural rock materials for concrete of the new generation was proposed and implemented;

- an efficient program of evaluation of structural strength as the complex characteristics, including a combination of the criteria of strength, reliability and durability of rocks, allowing on the one hand, a more reasonable approach to the selection of large filler for concrete of constructional purposes with high crack resistance, and the other-performing an analysis of the obtained dependencies from the standpoint of system-structural approach was proposed;

- we identified the nature of changes of relation $N_{1}\left(A_{1}\right) / N_{2}\left(A_{2}\right)$ of the amplitude-energy distribution of acoustic emission ultrasound pulses at the loading curve as the acoustic parameters that reflect the development of the deformation and destruction of materials at different scales, which are based on different physical phenomena, and which are the prognostic parameters of state of the material structure in the force impact, that allows to forecast the limit states of the structure of reviewed concrete components and establish a link between the level of stress and resistance of the material to the stable and unstable development of micro cracks of destruction Such control moves the researcher closer to the understanding of the process of destruction itself and to the identification of the materials parameters, which determine its crack resistance;

- the research results can be the basis for obtaining new physically based parameters of the mechanics and classification of rocks under crack resistance in order to implement the main idea of the development of composite construction materials, which is to combine high strength with good cracking resistance and improving of the concrete quality. 


\section{References}

Bartenev, O. А., Fadeyev, Yu. I. (1991) "Применение акустической эмиссии в механических испытаниях" (Application of the acoustic emission during mechanichal tests), Factory laboratory, 1, pp. 34-39. (in Russian)

Belikov, B. P., Aleksandrov, K. S., Ruzhova, T. V. (1970) "Упругие свойства породообразующих минералов и горных пород" (The elastic properties of the rock-forming minerals and rocks), Science, Moscow, Russia. (in Russian)

Bobryshev, A. N., Kozomazov, V. N., Babin, L. O., Solomatov, V. I. (1994) "Синергетика композитных материалов" (Synergetics of composite materials), SPA ORIUS, Lipetsk, Russia. (in Russian)

Evans, A. G., Langdon, T. G. (1980) "Конструкционная керамика" (Structural ceramic), Metallurgy, Moscow, Russia. (in Russian)

Greshnikov, V. A., Drobot, Yu. В. (1976) "Акустическая эмиссия" (Acoustic emission), Izdatelstvo standartov, Moscow, Russia. (in Russian)

Ivanov, V. I., Belov, V. М. (1981) "Акустико-эмиссионный контроль сварки и сварных соединений" (Acoustic and emission control of the welding and welded seam), Mashinostroyeniye, Moscow, Russia. (in Russian)

Lange, F. F. (1978) "Разрушение композитов с дисперсными частицами в хрупкой матрице" (The destruction of composite with the disperse particles in the brittle matrix), In: Cherpanov, G. P. (ed.) Композиционные материалы. Том 5. Разрушение и усталость (Composite materials, Vol. 5. Destruction and Fatigue), Moscow, Russia, pp. 9-57. (in Russian)

Lenain, J. C. (1981) "General Principles of acoustic emission", Material Evolution, 39 (11), pp. 1000-1002.

Makridin, N. I., Korolyov, Ye. V., Maksimova, I. N. (2007) "Метод акустической эмиссии в строительном материаловедении" (Method of acoustic emission in the constructive material engineering), In: Строительные материалы. Серия (Construction materials. Series), Science, 9, pp. 25-27. (in Russian)

Makridin, N. I., Korolyov, Ye. V., Maksimova, I. N. (2011) "Долговременная прочность модифицированной структуры цементного камня. Часть 2" (Long-term durability of the modified structure of the cement stone. Part 2), Строительные материалы (Construction materials), 7, pp. 72-75. (in Russian)
Makridin, N. I., Maksimova, I. N., Proshin, A. P., Sokolova, Yu. A. (2001) "Структура, деформативность, прочность и критерии разрушения цементных композитов" (Structure, deformability, strength and criteria of destruction of cement composite), Publishing company of Saratov University, Saratov, Russia. (in Russian)

Makridin, N. I., Skachkov, Yu. P., Maksimova, I. N., Surov, I. A. (2012) "Комплексная оценка механического поведения заполнителей бетона из горных пород" (Complex evaluation of the mechanics of the concrete fillers made of rocks), Региональная архитектура и строительство (Regional architecture and construction), 3(14), pp. 18-25. (in Russian)

Makridin, N. I., Solomatov, V. I., Panchenko, V. Р. (1986) "Влияние добавки суперпластификатора C-3 на характер разрушения высокопрочного бетона" (Influence of adding high range water reducer S-3 on the nature of high strength concrete destruction), Научно-технический сборник: Вопросы атомной науки и техники. Серия. Проектирование и строительство. (Scientific technical digest: Issues of nuclear science and technology. Series. Designing and construction), 1(22), pp. 47-56. (in Russian)

Muravin, G. B., Pavlovskaya, G. S., Likhotiko, A. D. (1982) Акустическая эмиссия при деформировании бетона" (Acoustic emission at deformation of the concrete), Дефектоскопия (Defect-detection), 12, pp. 3-13. (in Russian)

Perfilov, V. A. (2000) "Трещиностойкость бетонов: моногр" (Concrete crack resistance: monograph), VolgGASA, Volgograd, Russia. (in Russian)

Pochtovik, G. Ya., Tsybinoga, V. G., Gritsenko, B. S. (1977) "Сравнительное исследование процессов микротрещинообразования в растянутом бетоне методами акустической эмиссии и микроскопическим" (A comparative study of processes of micro-cracks forming in the stretched concrete using acoustic emission and microscopic methods), Труды МИСИ (Works of MISI (Moscow Construction Engineering Institute)), 51, pp. 111-117. (in Russian)

Sychyov, M. M. (1974) "Твердение вяжущих веществ" (Hardening of the binding agents), Stroyizdat, Leningrad, Russia. (in Russian) 